\title{
Comparison of neuronal activity in the supplementary motor area and primary motor cortex
}

\author{
Jun Tanji *, Hajime Mushiake \\ Department of Physiology, Tohoku University School of Medicine, 2-1 Seiryo-Cho, Aoba-Ku, Sendai 980, Japan
}

Accepted 22 August 1995

\begin{abstract}
Neuronal activity in the supplementary motor area (SMA) and primary motor cortex (MI) have been compared in many experiments during performance of many different motor tasks. On one hand, the activity in both areas may appear similar, especially when the motor task is simple. On the other hand, if the motor tasks are more demanding, neuronal activity in the SMA exhibits a variety of complex relationship to many different aspects of motor behavior, while the activity in MI is mostly related to execution of motor task itself. Of particular interest is the neuronal activity in the SMA during preparation and execution of motor tasks when no external cues for the retrieval of appropriate motor act is available. Temporal sequencing of multiple movements is a typical example of the kind of motor task that requires profound activity in the SMA.
\end{abstract}

Keywords: Supplementary motor area (SMA); Primary motor cortex (MI); Pre-SMA; Motor preparation; Motor sequence; Subhuman primate

\section{New concepts of motor areas in the medial frontal cortex}

Until recently, only one motor representation area was known to exist in the medial part of the frontal lobe, as described in classical reports [55,80]. However, it is now proposed that at least four somatomotor fields and one oculomotor field exist in the medial frontal cortex. [65]. Traditionally, the supplementary motor area (SMA) has been defined as a single motor area in the frontal agranular cortex, corresponding to medial part of Brodmann's area 6 . However, some indications for possible existence of heterogeneity in this region has been obtained [2,15,25,42]. On the basis of cytoarchitectonic analysis combined with cytochrome oxidase histochemistry and detailed ICMS studies, Rizzolatti and coworkers proposed a view that two motor areas exist in the region of the cortex traditionally defined as the SMA [41,44]. They termed the rostral and caudal areas as F6 and F3, largely corresponding to $6 \mathrm{ab}$ and $6 \mathrm{aa}$ of Vogts [78]. They also reported the existence of neuronal activity characteristic in mesial $6 \mathrm{ab}$, namely, the activity during arm reaching-grasping movements [57].

\footnotetext{
${ }^{*}$ Corresponding author. Fax: (81) (22) 272-2303.
}

Systematic attempts were made in our laboratory to determine whether it is possible to define two different areas unequivocally by a battery of physiological tests [45]. By implanting electrodes into the forelimb area of the MI, we found that field and unitary responses to electrical stimulation were distinct in the caudal part of mesial area 6 , but not in the rostral part. The caudal part was distinctly more microexcitable by the ICMS than the rostral part. Neuronal responses to visual stimuli prevailed in the rostral part, but somatosensory responses were rare. The opposite was true in the caudal part [24,79]. Furthermore, single-unit activity during performance of a trained motor task was quantitatively analyzed and compared in the same individuals. Phasic responses to visual cue signals indicating the direction of forthcoming arm-reaching movement were more abundant in the rostral part. Neuronal activity changes during the preparatory period for forthcoming movement were also more frequent in the rostral part. On the other hand, phasic, movement-related activity was more frequent in the caudal part. These physiological findings provide sufficient evidence that two separate motor areas exist in this part of the cortex traditionally defined as the SMA. We have proposed to use the term 'presupplementary motor area (pre-SMA)' for the rostral part (corresponding to F6), and the newly defined SMA (corresponding to F3 or SMA proper). 
Further support for defining two separate areas is also provided by histological findings $[16,45]$ that only the caudal part (newly defined SMA) has reciprocal connections with the MI, and that the pre-SMA but not the SMA receive massive projection from the prefrontal cortex (around the principal sulcus). Luppino et al. [40] performed a detailed analysis on the corticocortical connections of the pre-SMA (F6) and the SMA (F3), revealing differences in their connectivity. The pre-SMA receives a rich input from the area 46, anterior premotor cortex (their F5), anterior cingulate, and modest inputs from the inferior parietal lobule (PG and PFG) and the disgranular insula. On the other hand, the SMA is richly linked with the MI, posterior cingulate, and receives modest inputs from the PM, the postrolandic areas PC and PE of von Bonin and Bailey (1947), and the granular insula.

In the face of these new findings, it seems necessary in future studies to differentiate the two areas. Although experimental results have so far been reported in subhuman primates, it seems likely that the distinction into two separate motor areas is also applicable to human subjects. Fried et al. [19] observed large differences of stimulus effects in the rostral and caudal portions of the mesial frontal cortex. Only in the rostral part of stimulus sites did they elicit 'urge' in the subjects to initiate movements. Furthermore, Deiber et al. [14] have examined the question of which cortical areas are active during selection of movement by the PET technique. They compared rCBF changes while human subjects moved a joystick in a particular direction selected on the basis of information given under different conditions. The rostral part of the traditionally defined SMA differed in activity depending on how the selection was made, whereas the caudal part was similarly active under different conditions.

The existence of motor areas in the upper and lower banks of the cingulate sulcus has been established by anatomical studies that revealed connections of the cingulate cortex with cortical and subcortical motor centers $[3,26,43,47,48,77]$. Recent histological studies found the existence of two motor areas, i.e. rostral and caudal cingulate motor areas $[15,41]$. By recording neuronal activity during performance of a motor task, two movement-related foci were demonstrated in the cingulate cortex of monkey [60].

In addition to these somatomotor areas, an oculomotor area, defined as the supplementary eye field (SEF) [59], was found in the dorsomedial frontal cortex. The SEF lies rostrolateral to the SMA and pre-SMA, and is distinguishable from these two areas by its close relation to eye movements, and its anatomical connections to cortical and subcortical oculomotor centers. Some uncertainty has existed as to the exact location of the SEF and its relation to the SMA and pre-SMA. Confusion is caused partly by the use of strong electrical currents in evoking motor effects from medial motor areas. It must be cautioned that strong electrical stimulation, even with microelectrodes, will

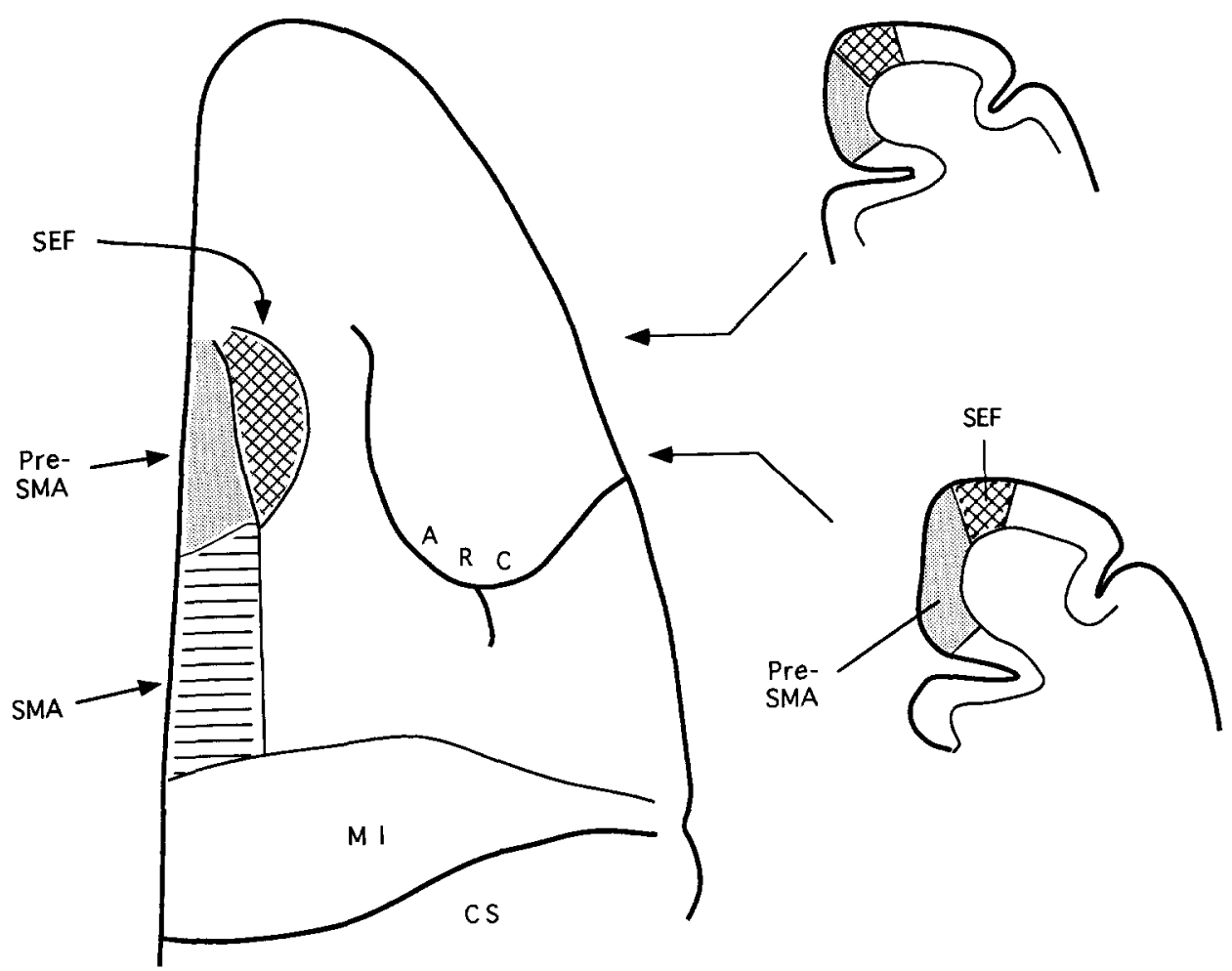

Fig. 1. Schematic drawing of the frontal cortex (viewed from top) to show approximate location of the SMA, pre-SMA, and SEF (supplementary eye field), according to the definition adopted in this article. 
evoke eye movements from a broad area, because of physical and transsynaptic current spread. For instance, current pulses of $400 \mu \mathrm{A}$ with $400 \mathrm{~ms}$ duration evoked saccades from a vast expanse of the dorsomedial frontal cortex [75]. The effective sites for evoking saccades shrinks dramatically when smaller currents were used, as typically described in Fig. 1 in the report by Huerta and Kaas [23]. By reducing the current to below $50 \mu \mathrm{A}$, the effective site was localized to a small area several $\mathrm{mm}$ medial to the superior limb of the arcuate sulcus, but outside of the medial wall. The location of the small low-threshold focus for evoking saccades was confirmed by other studies $[41,53]$. When a small amount of tracer (WGA-HRP) was injected into this portion of the cortex, that particular area was found to project to subcortical and cortical areas closely related to eye movement [23]. On the other hand, if tracers are injected medial or caudal to this particular area, connectivity was found with limb motor areas, but not with eye-movement related areas [40].

The three different areas in the dorsomedial frontal cortex are connected to entirely different cortical or subcortical areas. The SEF, but not the pre-SMA or SMA, is connected to the dorsolateral cortical oculomotor area, i.e., the frontal eye field (FEF) [63]. The SEF is connected to such brain stem oculomotor enters as the superior colliculus or the nucleus raphe interpositus $[23,61,62]$. The SEF, but not the pre-SMA or SMA, shares common terminal fields of corticostriatal projection with the FEF [53]. These findings provide sufficient basis for viewing the SEF as an entity separate from the pre-SMA and SMA. The spatial relation of SEF to SMA and pre-SMA can be schematically drawn as in Fig. 1. On the other hand, the participation of the SMA and pre-SMA in eye movements, are not to be completely excluded. Under special conditions requiring eye-hand coordination or complicated usage of eye and limbs, the latter areas may well take part in such motor tasks.

\section{Neurons in both SMA and MI are active in relation to relatively simple movements}

Because the definition of two areas, SMA and pre-SMA have only recently been established, it seems appropriate at this stage to compare the neuronal activity between traditionally defined SMA (including both SMA and pre-SMA) and $\mathrm{MI}$, on the basis of previous reports. It is now well known that the SMA, in addition to the MI, are active in such types of movements that does not require temporal or spatial control in any complex manner. Changes in rCBF have been reported during simple limb movements $[9,17,18,21]$. Movement related potentials have also been recorded in the SMA before flexion or extension of hand or arm joints $[5,27,30,74]$. In monkeys, neuronal activity in the SMA changes before and during movements that are not complexly organized, and therefore not particularly difficult to perform $[6,52,58,67,68,76]$. These findings indicate that the SMA is, at least in some way, involved in simple movements. It does not necessarily mean, however, that the activity in the SMA is more involved in simple, rather than complexly organized movements [64]. Nor does it mean that such activity is crucial or essential for execution of simple movements. The relative rCBF changes accompanying repetition of simple movements are smaller in the SMA than in the MI. Changes in neuronal activity in monkey SMA were found to be smaller in magnitude than in the MI [68] when monkeys were simply pressing keys following trigger signals (the difference may reflect more restricted and patchy forelimb representation in the SMA [8]). This finding is in line with results of microstimulation analysis [25]. They applied single micropulses into efferent focal zones in the SMA and MI. Post-pulse facilitation of muscle activity was prominent from the MI, but modest from the SMA. These reports suggest less significant participation of the SMA in execution of simple motor tasks than that of the MI.

\section{Neuronal activity in the SMA appear different from that in the MI}

In relation to certain types of movements, neuronal activity in the SMA may appear similar to that in the MI $[8,10]$. In such motor tasks, it was not possible to find clear differences in onset times of neuronal activity preceding movement onset, partly because individual differences among SMA and MI neurons are large. On the other hand, some differences in properties of neuronal activity in the two motor areas have been found [64]. Differences are detectable even in simple motor tasks. For instance, onset times of movement-related activity of a majority of MI neurons in reaction-time tasks are correlated with animal's reaction times. In the SMA, however, only a small number of neurons exhibit such correlation [68]. Another difference is the presence or absence of a selective relationship to a movement initiated differently. In MI neurons, the movement-related activity is similar, regardless of whether the movement is triggered by a visual, auditory or tactile signal $[32,68]$. In contrast, the activity of SMA neurons are often selective. An SMA neuron may be active when a movement is triggered by a visual signal, but not active when the same movement is triggered by an auditory signal [68]. Neuronal activity related to motor preparation is found in both MI and SMA [2]. However, if the preparatory process is more complicated, SMA neurons but not MI neurons are involved [73]. Furthermore, when subjects were required to use either right or left hand, or both hands together, the SMA activity was found to be strikingly different [70,71]. These reports provide evidence that properties of SMA neurons may appear different from MI 
neurons, depending on the nature of motor tasks required of subjects.

\section{Relation to motor preparation}

Kornhuber and Deecke were the first to find that slow negative shifts of the cortical DC potential (Bereitschaftspotential, BP, or readiness potential) can be recorded long before the execution of motor tasks $[12,13,29]$. The $\mathrm{BP}$, viewed as reflecting preparatory set and intention to act by these authors, has its maximum and earliest onset in fronto-central midline leads overlying the SMA and adjacent areas. This finding alone may not necessarily justify the interpretation that the BP reflects the activity in the SMA during preparation of limb movements. With subdural electrodes, the BP accompanying a simple limb movement was recorded more in the MI than in the SMA [51]. Results of the dipole source analysis [7] suggested that the predominant generator of the BP preceding simple finger movements may be in bilateral MI, rather than in the SMA. However, recent analysis of both electric and magnetic fields (EEG and MEG) in the same individuals reconfirmed the existence of an activity focus in the SMA [33]. They performed a three-dimensional analysis of MEG and EEG in a patient with infarction of the right SMA, thereby avoiding a possibility that magnetic fields of current dipole sources in the bilateral SMA may cancel each other. They were able to localize a current dipole source in the intact SMA starting $1200 \mathrm{~ms}$ prior to the initiation of voluntary movement of the right thumb. At about the same time of this MEG change, the initial component of the BP was recorded in EEG recordings. It should be added that the BP includes a long lasting phase (of more than $600 \mathrm{~ms}$ to several seconds), and a short lasting phase (of $<600 \mathrm{~ms}$ ) [38], associated with different processes of motor preparation [39]. These findings suggest that the SMA is active long before initiation of self-initiated digit movement, even if the motor task is simple.

Given these studies, detailed analysis of neuronal activity in the SMA related to motor preparation seems of interest. When monkeys were prepared to push or pull a handle in response to a forthcoming movement-trigger signal, the difference of the intended movements was reflected in the preparatory activity of SMA neurons [73]. Namely, the neuronal activity increased or decreased during the preparatory period, depending on whether the animal was intending (but not initiating) to push or pull a handle. In their study, it was also found that the magnitude of the preparatory activity in the SMA changed in parallel with the development of early muscle activity responding to a somesthetic stimulus as a trigger. In subsequent studies, the development of preparation for the direction of intended movement was found to be reflected in preparatory activity in the SMA $[2,31]$. However, the preparatory activity or motor set reflecting direction of intended movement is found in many other motor areas in the brain, including the MI $[20,46,56,66]$, and therefore, not a unique observation in the SMA. Are there any behavioral tasks that call for preparatory activity preferentially in the SMA?

Three studies have reported the presence of marked preparation-related neuronal activity in the SMA, with only a little in the MI, if any. In the first of these reports [69], monkeys were required to be prepared to move or not to move, depending on the forthcoming sensory signals. Unlike ordinary Go/noGO task, two different instructions told the animal to respond differently to two forthcoming signals. Under one condition, instruction A meant that the monkey had to press a key in response to signal $X$, but withdraw movement if the signal was $Y$. Under the next condition, instruction B asked the monkey to do the opposite. When observed during performance of this motor task, neurons in the SMA exhibited differential responses after the instruction $\mathrm{A}$ or $\mathrm{B}$. In the second report [71], SMA neurons were found to be differentially active depending on whether the animal were prepared to move a single hand or both hands. In the third report [50], a group of SMA neurons exhibited selective activity depending upon whether the monkeys were prepared to perform sequential button-press movement under visual guidance or based on memorized information. Thus, the SMA seem to be more involved in preparatory processes than the MI, during a number of different behavioral paradigm. It is important to know whether such preparatory activity in the SMA is transmitted to the MI. A partial answer to this question was obtained when SMA neurons exhibiting the preparatory activity was electrophysiologically identified to project to the MI [73]. It was also found that MI neurons having the preparatory type of activity receive inputs from the SMA, rather than from the thalamus or the parietal cortex [1].

\section{SMA neurons in organizing temporal sequences of multiple movements}

After ablation of the SMA and adjacent cortex, Laplane [37] reported that the only long-lasting deficit observed was disturbance of the alternating movements of the hands. Studies on cortical DC shifts revealed that the amplitudes of potentials in the medial frontal cortex were larger when motor tasks involved (1) sequential movements, (2) memorized motor sequence, and (3) bimanual coordination $[4,11]$. Subsequent studies $[28,34,36]$ extended these observations further. Of particular interest is the finding [35] that a large DC potential shifts were recorded when subjects were tapping different rhythms bimanually. These reports prompted detailed animal experiments to investigate how SMA neurons are involved in sequential motor tasks, especially when performance of a motor task requires storage of information in memory. Thus, we trained mon- 
keys to perform a sequential, button-press movement in two different conditions [50]. In one condition (visually guided), they reached to and pressed three buttons by following lights illuminated individually. In the other condition (memory guided), they had to remember a predetermined sequence of buttons to be pressed. More than half of the SMA neurons were preferentially or exclusively active before and during the memorized motor task, whereas a vast majority of MI neurons were similarly active in the visually guided and memorized task. Furthermore, in the memory condition, a subset of neuronal activity in the
SMA was of particular interest [49]. These neurons were active before or during only one type of sequential movement, reflecting motor memory. In a subsequent study [22], sequencing of multiple movements was required in the motor task. It was found that a majority of SMA neurons were preferentially active when the sequence was generated on the basis of memory.

In recent reports, Paassingham and his colleagues put forth a hypothesis that the SMA is essential in retrieving appropriate motor actions in the absence of external cues, on the basis of a series of lesion experiments [54]. A good

\section{SMA}

\section{(memory guided)}
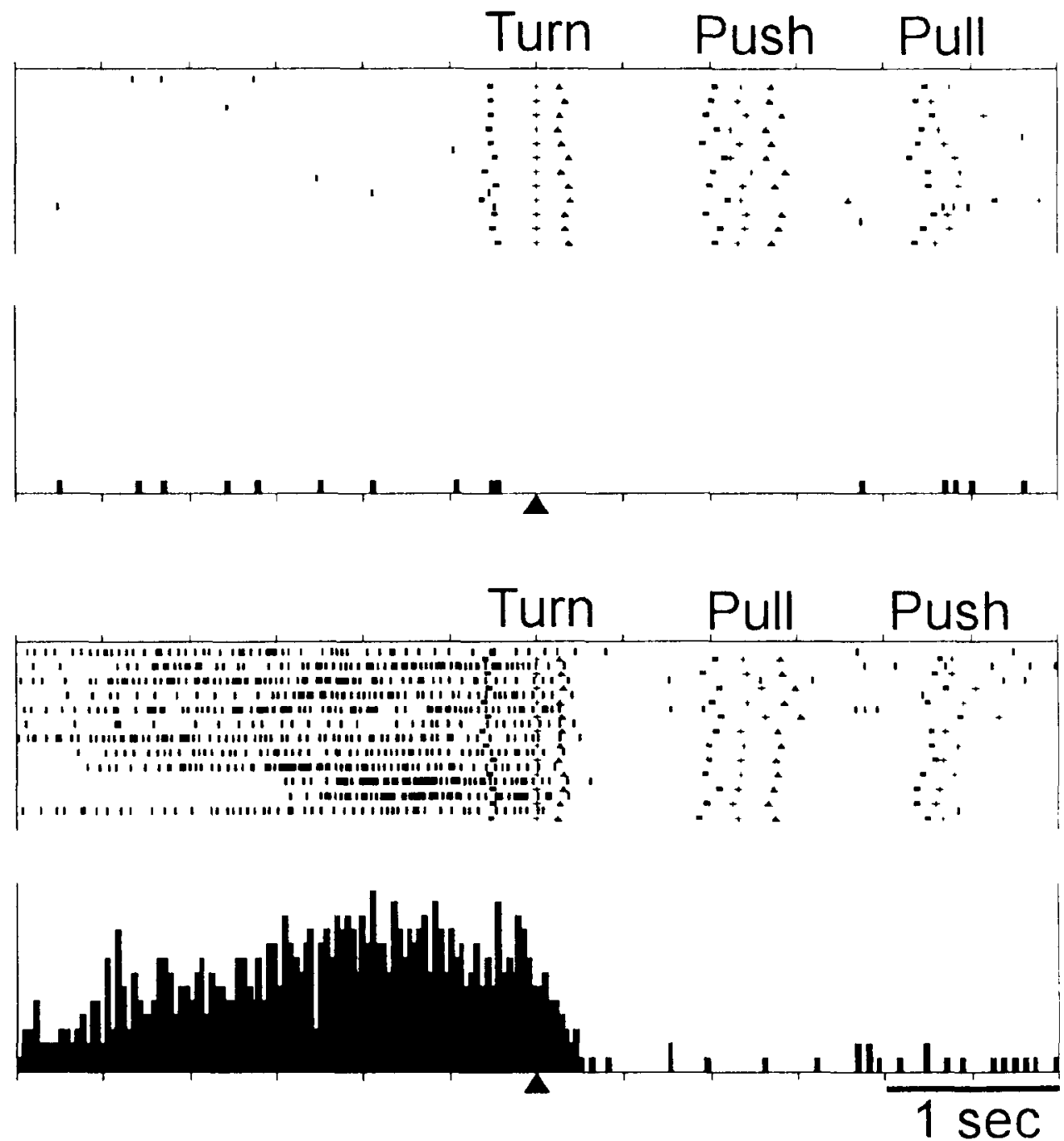

Fig. 2. Activity of a cell in the SMA exhibiting preferential relation to a specific order of three movements performed without sensory guidance. This cell is active during a waiting period, but only if the sequence of upcoming movements is in the order of turn, pull, and push (bottom). In raster displays, each row represents a trial, and dots represent individual discharges of this cell. Small squares, crosses, and triangles denote the time of occurrences of the trigger signal, movement onset, and target acquisition. In histograms, discharges over 12 trials are summated. Triangles at the bottom indicate the start of the first movement (adopted from [72]). 
test for the validity of this view is to require subjects to retrieve multiple movements in an appropriate temporal order, without sensory cues. We have very recently observed activity of SMA neurons while monkeys were performing three different movements (push, pull and turn with intervening pauses) in a variable but predetermined time sequence [72]. We have found that a group of SMA neurons were exclusively active in relation to a particular order of forthcoming movements guided by memory. Although these neurons (a typical example is shown in Fig. 2) were active during a waiting period before the first movement, the activity increased only if the order of the forthcoming three movements was a specific one (turnpull-push but not otherwise). We found another group of SMA neurons that were preferentially active during the interval between two specific movements. These neurons were active during a waiting period before execution of a particular movement, but only after the performance of another particular movement. We propose that these activity in the SMA contribute a signal about the order of forthcoming multiple movements, and are useful for retrieving appropriate action according to a memorized order. By observing activity of individual neurons, it was thus possible to demonstrate how SMA is involved in temporal sequencing of multiple motor action.

\section{References}

[1] Aizawa, H. and Tanji, J., Corticocortical and thalamocortical responses of neurons in the monkey primary motor cortex and their relation to a trained motor task, $J$. Neurophysiol., 71 (1994) 550-560.

[2] Alexander, G.E. and Crutcher, M.D., Preparation for movement: neural representations of intended direction in three motor areas of the monkey, J. Neurophysiol., 64 (1990) 133-150.

[3] Barbas, H. and Pandya, D.N., Architecture and frontal cortical connections of the premotor cortex (area 6) in the rhesus monkey, $J$. Comp. Neurol, 256 (1987) 211-228.

[4] Benecke, R. et al., Increase of the bereitschaftspotential in simultaneous and sequential movements, Neurosci. Lett., 62 (1985) 347352.

[5] Boschert, J., Hink, R.F. and Deecke, L., Finger movement versus toe movement-related potentials: further evidence for supplementary motor are (SMA) participation prior to voluntary action, Exp. Brain Res., 52 (1983) 73-80.

[6] Brinkman, C. and Porter, R., Supplementary motor area in the monkey: activity of neurons during a learned motor task, J. Neurophysiol., 42 (1979) 681-709.

[7] Bötzel, K. et al., Bereitschaftspotential: is there a contribution of the supplementary motor area?, Electroencephalogr. Clin. Neurophysiol., 89 (1993) 187-196.

[8] Chen, D. et al., Comparison of neural activity in the supplementary motor area and in the primary motor cortex in monkeys, Somatosens. Motor Res., 8 (1991) 27-44.

[9] Colebatch, J.G. et al, Regional cerebral blood blow during voluntary arm and hand movements in human subjects, J. Neurophysiol., 65 (1991) 1392-1401.

[10] Crutcher, M.D. and Alexander, G.E., Movement-related neuronal activity selectively coding either direction or muscle pattern in three motor areas of the monkey, J. Neurophysiol., 64 (1990) 151-163.

[11] Deecke, L., Bereitschaftspotential as an indicator of movement preparation in supplementary motor area and motor cortex. In R. Porter (Ed.), Motor Areas of the Cereberal Cortex, Wiley, 1987, 231-250.

[12] Deecke, L., Grozinger, B. and Kornhuber, H.H., Voluntary finger movement in man: cerebral potentials and theory, Biol. Cybern., 23 (1976) 99-119.

[13] Deecke, L., Scheid, P. and Kornhuber, H.H., Distribution of readiness potential, pre-motion positivity, and motor potential of the human cerebral cortex preceding voluntary figer movements, Exp. Brain Res., 7 (1969) 158-168.

[14] Deiber, M.-P. et al., Cortical areas and the selection of movement: a study with positron emission tomography, Exp. Brain Res., 84 (1991) 393-402.

[15] Dum, R.P. and Strick, P.L., The origin of corticospinal projections from the premotor areas in the frontal lobe, J. Neurosci., 11 (1991) $667-689$.

[16] Dum, R.P. and Strick, P.L., Premotor areas: nodal points for parallel efferent systems involved in the central control of movement. In: D.R. Humphrey and H.-J. Freund (Ed.), Motor Control: Concepts and Issues, John Wiley, New York, 1991, pp. 383-397.

[17] Foit, A. et al., Cortical activation during somatosensory stimulation and voluntary movement in man: a regional cerebral blood flow study, Electroencephalogr. Clin. Neurophysiol., 50 (1980) 426-436.

[18] Fox, P.T. et al., The role of cerebral cortex in the generation of voluntary saccades: a positron emission tomographic study, J. Neurophysiol., 54 (1985) 348-369.

[19] Fried, I. et al., Functional organization of human supplementary motor cortex studied by electrical stimulation, $J$. Neurosci., 11 (1991) 3656-3666.

[20] Georgopoulos, S.P., Crutcher, M.D. and Schwartz, A.D., Cognitive saptial-motor processes. 3. Motor cortical prediction of movement direction during an instructed delay period, Exp. Brain Res., 75 (1989) 183-194.

[21] Grafton, S.T., Woods, R.P. and Mazziotta, J.C., Within-arm somatotopy in human motor areas determined by positron emission tomography imaging of cerebral blood flow, Exp. Brain Res., 95 (1993) $172-176$.

[22] Halsband, U., Matsuzaka, Y. and Tanji, J., Neuronal activity in the primate supplementary, pre-supplementary, and premotor cortex during externally and internally instructed sequential movements, $\mathrm{Neu}$ rosci. Res., 20 (1994) 149-155.

[23] Huerta, M.F. and Kaas, J.H., Supplementary eye field as defined by intracortical microstimulation: connections in macaques, I. Comp. Neurol., 293 (1990) 299-330.

[24] Hummelsheim, H. et al., Sensory inputs to the agranular motor fields: a comparison between precentral, supplementary-motor and premotor areas in the monkey, Exp. Brain Res., 69 (1988) 289-298.

[25] Hummelsheim, H. et al., Further investigations of the efferent linkage of the supplementary motor area (SMA) with the spinal cord in the monkey, Exp. Brain Res., 65 (1986) 75-82.

[26] Hutchins, K.D., Martino, A.M. and Strick, P.L., Corticospinal projections from the medial wall of the hemisphere, Exp. Brain Res., 245 (1988) 1-6.

[27] Ikeda, A. et al., Movement-related potentials recorded from supplementary motor area and primary motor area, Brain, 115 (1992) 1017-1043.

[28] Kitamura, J. et al., Enhanced negative slope of cortical potentials before sequential as compared with simultaneous extensions of two fingers, Electroencephalogr. Clin. Neurophysiol., 86 (1993) 176182.

[29] Kornhuber, H.H. and Deecke, L., Hirnpotentialänderungen bei WillKürbewegungen und passiven Bewegungen des Menschen: Bereitschaftspotential und reafferente Potentiale, Pflïgers Arch. Ges. Physiol., 287 (1965) 1-17.

[30] Kristeva, R, et al., Movement-related potentials accompanying unilateral and bilateral finger movements with different inertial loads, Electroencephalogr. Clin. Neurophysiol., 75 (1990) 410-418. 
[31] Kurata, K. and Wise, S.P., Premotor and supplementary motor cortex in rhesus monkeys: neuronal activity during externally- and internally-instructed motor tasks, Exp. Brain Res., 72 (1988) 237 248.

[32] Lamarre, Y., Busby, L. and Spidalieri, G., Fast ballistic arm movements triggered by visual, auditory, and somesthetic stimuli in the monkey. I. activity of precentral cortical neurons, J. Neurophysiol., 50 (1983) 1343-1358.

[33] Lang, W. et al., Three-dimensional localization of SMA activity preceding voluntary movement. A study of electric and magnetic fields in a patient with infarction of the right supplementary motor area, Exp. Brain Res., 87 (1991) 688-695.

[34] Lang, W. et al., Negative cortical DC shifts preceding and accompanying simultaneous and sequential finger movements, Exp. Brain Res., 71 (1988) 579-587.

[35] Lang, W. et al., Supplementary motor area activation while tapping bimanually different rhythms in musicians, Exp. Brain Res., 79 (1990) 504-514.

[36] Lang, W. et al., Negative cortical DC shifts preceding and accompanying simple and complex sequential movements, Exp. Brain Res., 74 (1989) 99-104.

[37] Laplane, D. et al., Clinical consequences of corticectomies involving the supplementary motor area in man, J. Neurol. Sci., 34 (1977) 301-314.

[38] Libet, B., Wright, E.W. and Gleason, C.A., Readiness-potentials preceding unrestricted 'spontaneous' vs. pre-planned voluntary acts, Electroencephalogr. Clin. Neurophysiol., 54 (1982) 322-335.

[39] Libet, B., Wright, E.W. and Gleason, C.A., Preparation - or intention - to act, in relation to pre-event potentials recorded at the vertex, Electroencephalogr. Clin. Neurophysiol., 56 (1983) 367-372.

[40] Luppino, G. et al., Corticocortical connections of area F3 (SMAproper) and area F6 (Pre-SMA) in the macaque monkey, J. Comp. Neurol., 338 (1993) 114-140.

[41] Luppino, G. et al., Multiple representations of body movements in mesial area 6 and the adjacent cingulate cortex: an intracortical microstimulation study in the macaque monkey, J. Comp. Neurol., 311 (1991) 463-482.

[42] Macpherson, J.M. et al., Microstimlation of the supplementary motor area (SMA) in the awake monkey, Exp. Brain Res., 45 (1982) $410-416$.

[43] Martino, A.M. and Strick, P.L., Corticospinal projections originate from the arcuate premotor area, Brain Res., 404 (1987) 307-312.

[44] Matelli, M., Luppino, G. and Rizzolatti, G., Architecture of superior and mesial area 6 and the adjacent cingulate cortex in the macaque monkey, J. Comp. Neurol., 311 (1991) 445-462.

[45] Matsuzaka, Y., Aizawa, H. and Tanji, J., A motor area rostral to the supplementary motor area (presupplementary motor area) in the monkey: neuronal activity during a learned motor task, J. Neurophysiol., 68 (1992) 653-662.

[46] Mountcastle, V.B., Atluri, P.P. and Romo, R., Selective output-discriminative signals in the motor cortex of waking monkeys, Cerebral Cortex, 2 (1992) 277-294.

[47] Muakkassa, K.F. and Strick, P.L., Frontal lobe inputs to primate motor cortex: evidence for four somatotopically organized 'premotor' areas, Brain Res., 177 (1979) 176-182.

[48] Murray, E.A. and Coulter, J.D., Organization of corticospinal neurons in the monkey, J. Comp Neurol., 195 (1981) 339-365.

[49] Mushiake, H., Inase, M. and Tanji, J., Selective coding of motor sequence in the supplementary moto area of the monkey cerebral cortex, Exp. Brain Res., 82 (1990) 208-210.

[50] Mushiake, H., Inase, M. and Tanji, J., Neuronal activity in the primate premotor, supplementary, and precentral motor cortex during viusally guided and internally determined sequential movements, J. Neurophysiol., 66 (1991) 705-718.

[51] Neshige, R., Luders, H. and Shibasaki, H., Recording of movement-related potentials from scalp and cortex in man, Brain, 111 (1988) 719-736.

[52] Okano, K. and Tanji, J., Neuronal activities in the primate motor fields of the agranular frontal cortex preceding visually triggered and self-paced movement, Exp. Brain Res., 66 (1987) 155-166.

[53] Parthasarathy, H.B., Schall, J.D. and Graybiel, A.M., Distributed but convergent ordering of corticostriatal projections: analysis of the frontal eye field and the supplementary eye field in the macaque monkey, J. Neurosci., 12 (1992) 4468-4488.

[54] Passingham, R.E., The Frontal Lobes and Voluntary Action, Oxford psychology Series no. 21, 1993, Oxford, Oxford University Press.

[55] Penfield, W. and Welch, K., The supplementary motor area of the cerebral cortex. A clinical and experimental study, Arch. Neurol. Psychiatr., 66 (1951) 289-317.

[56] Requin, J., Lecas, J.-C. and Vitton, N., A comparison of preparation-related neuronal activity changes in the prefrontal, premotor, primarymotor and posterior parietal areas of the monkey cortex: preliminary results, Neurosci. Lett., 111 (1990) 151-156.

[57] Rizzolatti, G. et al., Neurons related to reaching-grasping arm movements in the rostral part of area 6 (area 6a), Exp. Brain Res., 82 (1990) 337-350.

[58] Romo, R. and Schultz, W., Neuronal activity preceding self-initiated or externally timed arm movements in area 6 of monkey cortex, Exp. Brain Res., 67 (1987) 656-662.

[59] Schlag, J. and Schlag-Rey, M., Evidence for a supplementary eye field, J. Neurophysiol., 57 (1987) 179-200.

[60] Shima, K. et al., Two movement-related foci in the primate cingulate cortex observed in signal-triggered and self-paced forelimb movements, J. Neurophysiol., 65 (1991) 188-202.

[61] Shook, B.L., Schlag-Rey, M. and Schlag, J., Primate supplementary eye field: I. Comparative aspects of mesencephalic and pontine connections, J. Comp. Neurol., 301 (1990) 618-642.

[62] Shook, B.L., Schlag-Rey, M. and Schlag, J., Primate supplementary eye field: II. Comparative aspects of connections with the thalamus, corpus striatum, and related forebrain nuclei, J. Comp. Neurol., 307 (1991) 562-583.

[63] Stanton, G.B., Bruce, C.J. and Goldberg, M.E., Topography of projections to the frontal lobe from the macaque frontal eye fields, J. Comp. Neurol., 330 (1993) 286-301.

[64] Tanji, J., The neuronal activity in the supplementary motor area of primates, Trends NeuroSci., 27 (1984) 282-285.

[65] Tanji, J., The supplementary motor area in the cerebral cortex, Neurosci. Res., 19 (1994) 251-268.

[66] Tanji, J. and Evarts, E.V., Anticipatory activity of motor cortex neurons in relation to direction of an intended movement, $J$. Neurophysiol., 39 (1976) 1062-1068.

[67] Tanji, J. and Kurata, K., Neuronal activity in the cortical supplementary motor area related with distal and proximal forelimb movements, Neurosci. Lett., 12 (1979) 201-206.

[68] Tanji, J. and Kurata, K., Comparison of movement-related activity in two cortical areas of primates, J. Neurophysiol, 48 (1982) $633-653$.

[69] Tanji, J. and Kurata, K., Contrasting neuronal activity in supplementary and precentral motor cortex of monkeys. I. Responses to instructions determining motor responses to forthcoming signals of different modalities, J. Neurophysiol., 53 (1985) 129-141.

[70] Tanji, J., Okano, K. and Sato, K.C., Relation of neurons in the nonprimary motor cortex to bilateral hand movement, Nature, 327 (1987) 618-620.

[71] Tanji, J., Okano, K. and Sato, K.C., Neuronal activity in cortical motor areas related to ipsilateral, contralateral, and bilateral digit movements of the monkey, J. Neurophysiol., 60 (1988) 325-343.

[72] Tanji, J. and Shima, K., Role for supplementary motor area cells in planning several movements ahead, Nature, 371 (1994) 413-416.

[73] Tanji, J., Taniguchi, K. and Saga, T., Supplementary motor area: 
neuronal response to motor instructions, $J$. Neurophysiol, 43 (1980) $60-68$.

[74] Tarkka, I.M. and Hallet, M., Topography of scalp-recorded motor potentials in human finger movements, J. Clin. Neurophysiol., 8 (1991) 331-341.

[75] Tehovnik, E.J. and Lee, K., The dorsomedial frontal cortex of the rhesus monkey: topographic representation of saccades evoked by electrical stimulation, Exp. Brain Res., 96 (1993) 430-442.

[76] Thaler, D.E., Rolls, E.T. and Passingham, R.E., Neuronal activity of the supplementary motor area (SMA) during internally and externally triggered wrist movements, Neurosci. Lett., 93 (1988) 264-269.

[77] Vogt, B.A., Pandya, D.N. and Rosene, D.L., Cingulate cortex of the rhesus monkey: I. Cytoarchitecture and thalamic afferents, J. Comp. Neurol, 262 (1987) 256-270.

[78] Vogt, C. and Vogt, O., Allgemeinere Ergebnisse unserer Hirnforschung, J. Psychol. Neurol. (LPZ), 25 (1919) 279-439.

[79] Wiesendanger, M., Hummelsheim, H. and Bianchetti, M., Sensory input to the motor fields of the agranular frontal cortex: a comparison of the precentral, supplementary motor and premotor cortex, Behav. Brain Res., 18 (1985) 89-94.

[80] Woolsey, C.N. et al., Patterns of localization in precentral and 'supplementary' motor areas and their relation to the concept of a premotor area, Res. Publ. Assoc. Nerı. Ment. Dis., 30 (1952) $238-264$. 